\title{
Synthesis and Characterisation of Aqueous Haemoglobin-based Microcapsules Coated by Genipin-Cross-Linked Albumin
}

Kai Melvin Schakowski ${ }^{a^{*}}$, Jürgen Linders ${ }^{\mathrm{b}, \mathrm{d}}$, Katja Bettina Ferenz ${ }^{\mathrm{c}, \mathrm{d}}$, Michael Kirsch $^{\mathrm{a}}$

${ }^{a}$ Institute of Physiological Chemistry, University of Duisburg-Essen, University Hospital Essen, Hufelandstraße 55, 45147 Essen, Germany

${ }^{b}$ Department of Physical Chemistry, University of Duisburg-Essen, Universitätsstraße 5, 45141 Essen, Germany

${ }^{c}$ Institute of Physiology, University of Duisburg-Essen, University Hospital Essen, Hufelandstraße 55, 45147 Essen, Germany

${ }^{d}$ Center for Nanointegration Duisburg-Essen (CeNIDE), University of Duisburg-Essen, Carl-Benz-Straße 199, 47057 Duisburg, Germany

*Universitätsklinikum Essen, Hufelandstraße 55, 45147 Essen, Kai Melvin Schakowski, Institut für Physiologische Chemie, kai.schakowski@uk-essen.de 


\section{Synthesis and Characterisation of Aqueous Haemoglobin-based Microcapsules Coated by Genipin-Cross-Linked Albumin}

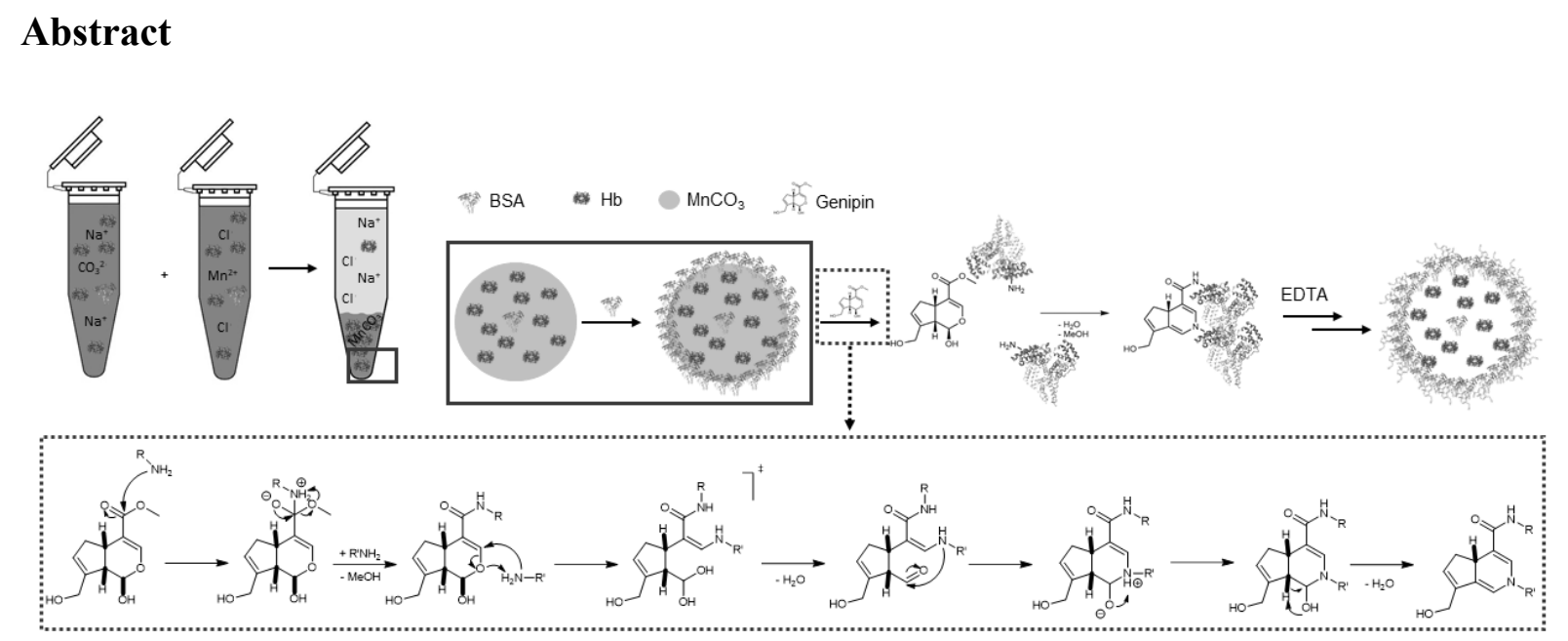

Figure 1. After co-precipitation of $\mathrm{MnCO} 3$ and $\mathrm{Hb}$, BSA forms an additional layer around the $\mathrm{MnCO} 3 / \mathrm{Hb}$-particle. BSA within this layer is then cross-linked by addition of genipin and later the $\mathrm{MnCO} 3$ in the core of the particle is dissolved by EDTA, resulting in a stable shell of BSA around the $\mathrm{Hb}$-core. The mechanism of cross-linkage by genipin has been described by Butler et al. in 2003. R represents the amino-sidechains of BSA.

Bovine serum albumin (BSA)-coated haemoglobin ( $\mathrm{Hb}$ )-microcapsules prepared by co-precipitation of $\mathrm{Hb}$ and $\mathrm{MnCO}_{3}$ may present an alternative type of artificial blood substitute. Prepared microcapsules were analysed by Scanning electron microscopy (SEM) and Respirometry, cytotoxicity was evaluated by addition of microcapsules to murine fibroblast-derived cell line L929 (American Type Culture Collection, NCTC clone 929 of strain L). The capsules come along with a mean diameter of approximately $0.6 \mu \mathrm{m}$ and a mean volume of $1.13 \cdot 10^{-19} \mathrm{~L}$, thus an average human red blood cell with a volume of $9 \cdot 10^{-14} \mathrm{~L}$ is about 800,000 times bigger. Hb-microcapsules are fully regenerable by ascorbic acid and maintain oxygen affinity because oxygen is able to pass the BSA wall of the capsules and thereby binding to the ferrous iron of the haemoglobin entity. Therefore, these microcapsules present a suitable type of potential artificial haemoglobin-based oxygen carrier (HbOC).

Keywords: Albumin, Cross-linking, Microcapsules, Haemoglobin, Oxygen Carrier, Genipin 


\section{Introduction}

Every day more than 200,000 units of erythrocyte concentrate are needed for transfusion after fatal accidents or during surgery involving the loss of huge amounts of blood. Despite the annual need for more than 85 million units of packed red blood cells (RBCs) worldwide (e.g. about four million units in Germany and 12-16 million units in the USA), a constant decline in willingness to donate blood therefore brings up severe difficulties to handle (Riedel et al. 2000, Diez-Silva et al. 2010, Sharma et al. 2011, Müller et al. 2015, Remy and Spinella 2016, García-Roa et al. 2017, Henseler 2019). Besides the well-known limits of compatibility among the different blood groups, logistical factors achieve increased importance (Chen et al. 2009). Since hospitals must ensure adequate supply of RBCs (and of other blood components) for transfusion and because the number of blood donations is retrograde in highly developed countries, medical institutions must import RBCs and this can evoke a bottle-neck of the supply when the travel time of the units determines the availability.

Shortage on erythrocytes always coincides with shortage on long-term oxygen supply, as a sufficient quota of haemoglobin must be assured in order to secure adequate sustenance. Due to scarcity on RBCs, alternative ways of sustaining blood oxygen levels must be deduced. Within the last years artificial blood substitutes have gained more and more attention because of the above mentioned decrease of available RBCs (Ruchalla 2013, Njoku et al. 2015, Chung et al. 2016, Ellingson et al. 2017, Taguchi et al. 2017, Ferenz and Steinbicker 2019). Since the application of a pure solution of haemoglobin is impractical due to the enormous nephrotoxicity and short circulation time (Chang 2006), several different attempts have been made to create biocompatible artificial oxygen carriers, based on either perfluorocarbons or haemoglobin that needs to be encapsulated in protective shells in any case (Bauer et al. 2010, von Storp et al. 2012, Ferenz et al. 2013, Sakai et al. 2013, Stephan et al. 2014, Wrobeln, Laudien, et al. 2017, Wrobeln, Schlüter, et al. 2017).

The most commonly used assay for cross-linkage of albumin is the method of glutaric dialdehyde cross-linkage (Ling 1961, Mamedova et al. 2002, Choi et al. 2006, Bychkova et al. 2013). This method bears the disadvantage that excess toxic glutaric dialdehyde must be removed from the reaction mixture by using $\mathrm{LiAlH}_{4}$ or $\mathrm{NaBH}_{4}$, both highly inflammable chemicals in combination with aqueous environments.

In the present study, we focused on a technique that makes use of the high loading capacity of inorganic carbonates. By co-precipitation of haemoglobin and $\mathrm{MnCO}_{3}$ followed by adsorption of cross-linked albumin on the surface of the $\mathrm{MnCO}_{3}$, haemoglobin is captured within a shell of albumin, that was cross-linked with genipin or derivates of benzoic acid. Dissolution of the $\mathrm{MnCO}_{3}$ template finally leads to porous particles of cross-linked albumin with encapsulated haemoglobin. Although the technique of cross-linking proteins by genipin is an established one (Butler et al. 2003, Yoo et al. 2011), the preparation of genipin linked albumin shells as part of artificial oxygen carriers is a novel procedure. 


\section{Experimental}

\section{Materials}

Ascorbic acid, 4-Bromomethyl-3-nitrobenzoic acid (BNBA), Bovine serum albumin fraction V (BSA), Dimethyl sulfoxide anhydrous (DMSO), 4-(4,6-Dimethoxy-1,3,5-triazin-2-yl)-4-methylmorpholinium chloride (DMT-MM), Ethylenediaminetetraacetic acid disodium salt dihydrate ( $\mathrm{Na}_{2} \mathrm{EDTA}$ ), Haemoglobin from bovine blood $(\mathrm{Hb})$, Manganese(II) chloride tetrahydrate, Minimum Essential Medium Eagle (MEM), sodium dithionite (SDT) and Triton X-100 were purchased from Sigma-Aldrich (Darmstadt, Germany); Sodium bicarbonate, Sodium carbonate anhydrous, Sodium hydroxide, Potassium cyanide, Potassium ferricyanide and Monopotassium phosphate were purchased from Merck (Darmstadt, Germany); Boric acid, Glucose, L-Glutamine, Sodium chloride, Sodium dodecyl sulphate ultra-pure (SDS), Disodium phosphate dehydrate and Potassium chloride were purchased from Carl Roth (Karlsruhe, Germany); Ringer's solution was purchased from Fresenius Kabi (Bad Homburg, Germany); Gibco Fetal bovine serum (FBS), Gibco Pen Strep and Gibco 0.05\% Trypsin-EDTA were purchased from Thermo Fisher Scientific (Schwerte, Germany).

\section{Preparation of Hb-Microcapsules}

$\mathrm{Hb}$-microcapsules were prepared by modifying methods that were originally developed by XIONG et al. (Xiong et al. 2012, 2013, Li et al. 2017). Since lately cross-linkage of proteins by genipin has gained attention (Butler et al. 2003, Yoo et al. 2011, Shahgholian et al. 2017), the chemical cross-linkers BNBA and DMT-MM used by XIONG et al. were replaced by genipin, a natural substance derived from the iridoid glycoside geniposide. Although genipin does not serve as a cross-linker as naturally purposed, it's chemical properties can be used to link amino-groups (Djerassi et al. 1960). The mechanism of linking amino-groups by genipin has first been described by BUTLER et al. in 2003 (s. Figure 1) (Butler et al. 2003).

A volume of $15 \mathrm{~mL}$ of aqueous solutions containing either $0.25 \mathrm{mM} \mathrm{Na}_{2} \mathrm{CO}_{3}$ or $\mathrm{MnCl}_{2}$ as well as $10 \mathrm{mg} \cdot \mathrm{mL}^{-1} \mathrm{Hb}$ and $1 \mathrm{mg} \cdot \mathrm{mL}^{-1}$ BSA were mixed under continuous stirring in a $100 \mathrm{~mL}$ beaker. After stirring for two more minutes, $150 \mathrm{mg}$ BSA were added slowly under continuous stirring for five more minutes. The resulting suspension of $\mathrm{BSA}$-coated $\mathrm{MnCO}_{3}$ particles with entrapped $\mathrm{Hb}$ was centrifuged (1000 g, $1 \mathrm{~min}$.). The residue was washed three times with $60 \mathrm{~mL}$ of Ringer's solution each, while the supernatants were collected separately and photometrically checked for their concentrations of remaining $\mathrm{Hb}$. After washing, the residue of particles was suspended in either $60 \mathrm{~mL}$ of DMSO containing $37.5 \mathrm{mg}$ BNBA and $45 \mathrm{mg}$ DMT-MM or $60 \mathrm{~mL}$ of an aqueous solution of genipin differing from $0.188-4 \mathrm{mM}$ genipin. The re-suspended particles were shaken for 24 hours at room temperature. The DMSO-treated fraction was then washed three times with $60 \mathrm{~mL}$ DMSO each. From now on both fractions were treated equally. They were washed three times with $60 \mathrm{~mL}$ of Ringer's solution each and then re-suspended in $100 \mathrm{~mL}$ of $0.2 \mathrm{M} \mathrm{Na}_{2}$ EDTA-solution at $\mathrm{pH}$ 7.4. The suspension was shaken by hand until all visible solid had completely dissolved. If necessary, samples were sonicated in order to 
complete the breakdown of the solid. Dissolution of the $\mathrm{MnCO}_{3}$ by dissociated $\mathrm{Na}_{2}$ EDTA resulted in constructs that trapped $\mathrm{Hb}$ into the inside of the cross-linked BSA-shell, thus EDTA chelating $\mathrm{Mn}^{2+}$ to form a soluble MnEDTA complex. The fractions were centrifuged (1000 g, $1 \mathrm{~min}$.) and the residue was washed two times with $80 \mathrm{~mL}$ EDTA-solution, then three times with $60 \mathrm{~mL}$ of Ringer's solution before being re-suspended in $5 \mathrm{~mL}$ of Ringer's solution each and stored at $4{ }^{\circ} \mathrm{C}$ under exclusion of light.

\section{Characterisation of Hb-Microcapsules}

\section{Photometry}

Concentrations of $\mathrm{Hb}$ stock solutions were determined by the cyanmethaemoglobin-method (Drabkin and Austin 1932, van Kampen and Zijlstra 1961) as well as the SDS-Hb-method (Oshiro et al. 1982, Karsan et al. 1993, Kalyan Chakravarthy et al. 2012) on a UV-VIS Specord S 600 spectrophotometer (Analytik Jena, Jena, Germany). Concentrations of $\mathrm{Hb}$ in the supernatants were determined by the SDS$\mathrm{Hb}$-method sole, due to residue manganese interfering with the cyanide of the transforming reagent.

For the cyanmethaemoglobin-method, $1 \mathrm{~mL}$ of transforming reagent containing $330 \mathrm{mg}$ potassium ferricyanide, $400 \mathrm{mg}$ sodium hydroxide, $150 \mathrm{mg}$ potassium cyanide and $125 \mathrm{mg}$ boric acid per litre was added to $40 \mu \mathrm{L}$ of aqueous $\mathrm{Hb}$-solutions of different concentrations. The mixtures were incubated for 10 minutes at room temperature and measured against a mixture of $40 \mu \mathrm{L}$ Millipore water and $1 \mathrm{~mL}$ transforming reagent at $\lambda=546 \mathrm{~nm}$.

For the SDS-Hb-method, $450 \mu \mathrm{L}$ of Millipore water were added to $50 \mu \mathrm{L}$ of aqueous $\mathrm{Hb}$-solutions of different concentrations and stirred with $500 \mu \mathrm{L}$ of $0.06 \%$ aqueous SDS-solution. After incubation for 15 minutes at room temperature, the mixtures were measured against $500 \mu \mathrm{L}$ of Millipore water and $500 \mu \mathrm{L}$ of SDS-solution at $\lambda=540 \mathrm{~nm}$.

Since both, cyanmethaemoglobin and SDS-haemoglobin strictly obey the law of LAMBERT and BEER (Lambert 1760), extinction coefficients could be determined by linear regression $(n=5)$, as depicted in Figure 2. All standard deviations are well below $10^{-3}$ and hence not shown. 

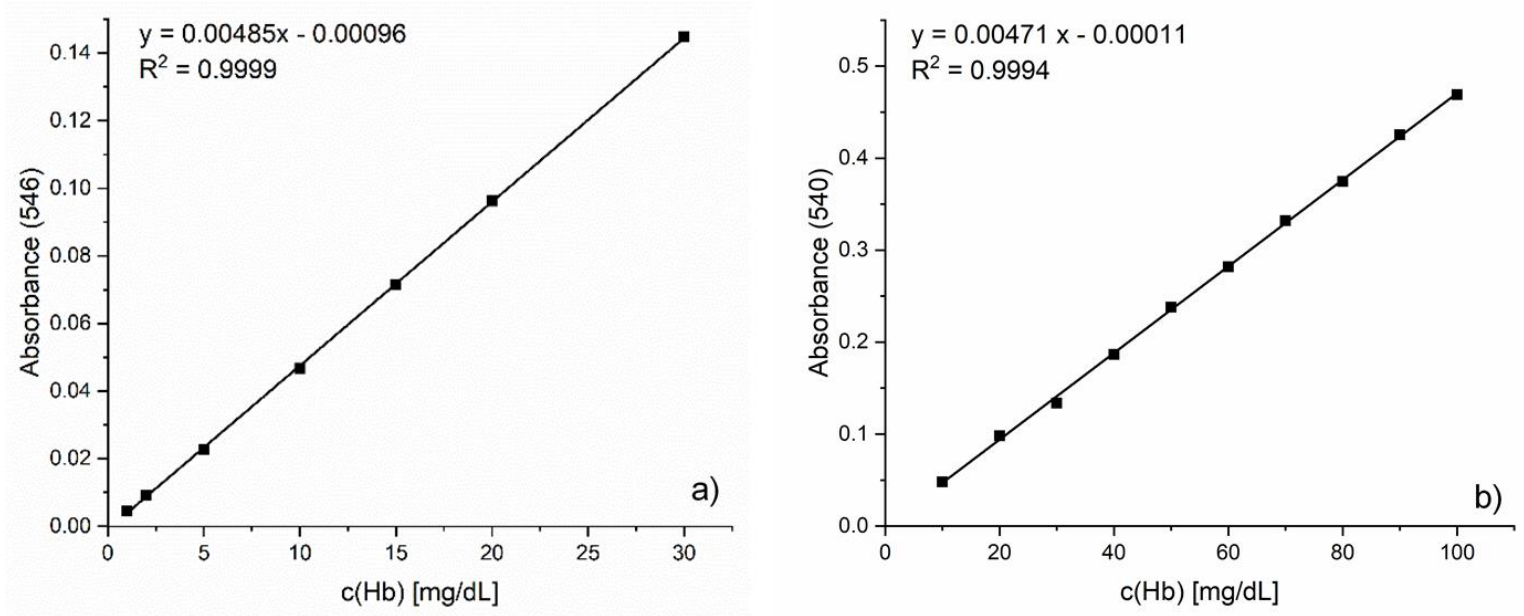

Figure 2. Determination of extinction coefficients for cyanmethaemoglobin(CN)- (a) and SDS-Hbmethod (b) by linear regression ( $\mathrm{n}=5$ each); Different concentrations of aqueous Hb-solutions were added to transforming reagent $(\mathrm{CN})$ or SDS-solution, respectively. After incubation, absorption of the solutions was measured at $546 \mathrm{~nm}(\mathrm{CN})$ or $540 \mathrm{~nm}(\mathrm{SDS})$ and plotted against the concentrations.

The entrapment efficiency (EE) was calculated by determining the concentration of $\mathrm{Hb}$ in the stock solution $\left([\mathrm{Hb}]_{0}\right)$ and in the supernatants after co-precipitation with $\mathrm{MnCO}_{3}\left([\mathrm{Hb}]_{s}\right)$ and each washing step. For there was hardly any $\mathrm{Hb}$ detectable in the supernatants of each washing step, the EE was calculated according to $\mathrm{EE}=\left(1-[\mathrm{Hb}]_{\mathrm{s}} /[\mathrm{Hb}]_{0}\right) \cdot 100 \%$.

\section{Respirometry}

Respirometry was performed on an Oroboros Oxygraph-2k (Oroboros Instruments, Innsbruck, Austria).

In order to determine the oxygen binding capacity of the prepared microcapsules, $1 \mathrm{~mL}$ of the suspension of $\mathrm{Hb}$-microcapsules or freshly prepared free $\mathrm{Hb}$ solution (same $\mathrm{Hb}$-concentration as in $\mathrm{Hb}$ microcapsules' suspension, control) was mixed with $1 \mathrm{mg}$ of sodium dithionite (SDT). The chambers of the Oxygraph were filled with $50 \mathrm{mM}$ sodium phosphate buffer ( $\mathrm{pH} 7.4)$ and equilibrated with air. After equilibrium of the chambers was reached, $50 \mu \mathrm{L}$ of the prepared microcapsules' suspension or free $\mathrm{Hb}$ solution was added and the decrease in oxygen concentration within the chamber was measured. The concentration of $\mathrm{Hb}$ for each control was calculated individually from the encapsulation efficiency of each sample.

For displaying the regenerative capacity, volumes of a concentrated suspension of $\mathrm{Hb}$ microcapsules and a solution containing $500 \mu \mathrm{g} \cdot \mathrm{mL}^{-1}$ potassium ferricyanide were mixed in ratio 1:2 and incubated over night at $4{ }^{\circ} \mathrm{C}$. The chambers of the Oxygraph were filled with $50 \mathrm{mM}$ sodium phosphate buffer ( $\mathrm{pH}$ 7.4) and equilibrated with air. After equilibrium of the chambers was reached, $50 \mu \mathrm{L}$ of the before prepared solution was added. Then $150 \mu \mathrm{L}$ of a freshly prepared $10 \mathrm{mg} \cdot \mathrm{mL}^{-1}$ solution of ascorbic acid was added and decrease of oxygen concentration within the chambers was measured. 


\section{Dynamic light-scattering}

Dynamic light-scattering (DLS) was performed on a Nano-Flex apparatus (Particle Metrix, Meerbusch, Germany) by using Microtrac FLEX 11.0.05 software. $500 \mu \mathrm{L}$ of the microcapsules' suspension was transferred into a $2 \mathrm{~mL}$ micro reaction vessel (Eppendorf, Hamburg, Germany) and measured three times for 60 seconds against Ringer's solution for set zero.

\section{Scanning Electron Microscopy}

Scanning Electron Microscopy (SEM) was performed on a FIB-SEM 540 Crossbeam (Carl Zeiss, Oberkochen, Germany) in the Electron Microscopy Unit of the Imaging Center Essen (University Hospital Essen, Essen, Germany). Samples were prepared by dehydration in an ascending five-step ethanol series from $30-96 \%$ followed by immersion in $100 \%$ pure dried ethanol three times, for 10 minutes each. Samples were dried by critical point drying with $\mathrm{CO}_{2}$ and sputter coated with $\mathrm{Pt} / \mathrm{Pd}$. Every image taken was provided with the exact data of capturing.

\section{NATIVE POLYACRYLAMIDE GEL ELECTROPHORESIS}

Gradient Polyacrylamide Gel Electrophoresis (PAGE) was used to separate oligomers of BSA from monomer BSA. A gradient from 4\%-16\% was used. Proteins were stained by a solution of $2.5 \mathrm{~g}$ Coomassie brilliant blue $\mathrm{R} 250$ in a mixture of $500 \mathrm{~mL}$ methanol, $100 \mathrm{~mL}$ acetic acid completed to $1000 \mathrm{~mL}$ using Millipore water. For destaining the same solution without Coomassie was used.

\section{CELL CULTURE AND MEASUREMENTS OF LACTATE-DEYDROGENASE (LDH)-ACTIVITIES}

Measurements on LDH-activity and other commonly measured clinical parameters were performed on a Respons ${ }^{\circledR 920}$ (DiaSys Diagnostic Systems GmbH, Holzheim, Germany).

The standard cytotoxicity model of murine fibroblast-derived cell line L929 (American Type Culture Collection, NCTC clone 929 of strain L) was used for the experiments. Cells were cultured in minimum essential medium (MEM) Eagle supplemented with $25 \mathrm{mM}$ sodium bicarbonate, $10 \% \mathrm{FBS}$, $2 \mathrm{mM}$ L-glutamine, and 100 units $/ \mathrm{mL}$ penicillin $\mathrm{G}$ and $0.1 \mathrm{mg} / \mathrm{mL}$ streptomycin in $75 \mathrm{~cm}^{2}$ plastic flasks at $37{ }^{\circ} \mathrm{C}$ in a humidified atmosphere of $95 \%$ air and $5 \% \mathrm{CO}_{2}$. Subcultures were obtained by trypsinisation (0.05\% trypsin-EDTA) (Lomonosova et al. 1998). For experimental use, cells were transferred to 6-well plates.

For toxicity experiments of prepared microcapsules counting of the cells right before beginning of the experiments showed an average number of about 1,000,000 cells per well. The medium was removed and cells were washed with $2.0 \mathrm{~mL}$ of PBS buffer before $2.0 \mathrm{~mL}$ of the solutions to test were added. All test-solutions contained Ringer's solution $+4.5 \mathrm{~g} / \mathrm{L}$ glucose and a) $3 \mathrm{mg} / \mathrm{ml} \mathrm{BSA} \mathrm{(g-BSA)}$ or b) $2.5-5 \mathrm{vol} \%$ of microcapsules as $\mathrm{HbOCs}$ or c) BSA and free haemoglobin in different concentrations $(\mathrm{Hb})$ or d) no further ingredients (blank), respectively.

Wells were incubated at described conditions for $60-300$ minutes before $1 \mathrm{~mL}$ of the supernatant was removed for $\mathrm{LDH}$ measurement $\left(\mathrm{LDH}_{\mathrm{t}}, \mathrm{t} \in\{60,120,180,240,300\}\right)$. At the end of the experiment, cells were lysed for $15 \mathrm{~min}$ at $37{ }^{\circ} \mathrm{C}$ by the addition of $200 \mu \mathrm{L}$ of $25 \%$ Triton X-100 followed by shaking before $1 \mathrm{~mL}$ of the remaining solution was removed for $\mathrm{LDH}$ measurement to obtain the maximum 
possible amount of $\mathrm{LDH}$ that could have been released $\left(\mathrm{LDH}_{\max }\right)$. Total lysis of cells was confirmed by visual inspection under an optical microscope.

All samples were centrifuged shortly to remove larger cell debris and HbOCs before performing photometric measurements on LDH-activity using the automatic LDH protocol of the Respons®920 according to the manufacturer's instructions (Instructions for use (respons 920) 2019).

For statistical analysis, t-tests were performed assuming two-tailed distributions and unequal variances.

Relative cell damage $\left(\mathrm{d}_{\mathrm{r}} \%\right)$ has been calculated according to $\mathrm{d}_{\mathrm{r}} \%=\left(\mathrm{LDH}_{\mathrm{t}} / \mathrm{LDH}_{\max }\right) \cdot 100 \%$.

Tests on interference between $5 \mathrm{vol} \% \mathrm{HbOCs}$ and commonly measured clinical parameters have been performed by diluting standard serums obtained from DiaSys Diagnostic Systems GmbH (Holzheim, Germany) with different quantities of microcapsules solutions or Ringer's solution, respectively. All samples were centrifuged shortly to remove $\mathrm{HbOCs}$ before performing measurements on activities of alanin transaminase (ALT), aspartate transaminase (AST), creatine kinase (CK) and LDH as well as concentrations of creatinine (Crea) and Urea.

\section{QUANTITATIVE NUCLEAR MAGNETIC RESONANCE MEASUREMENTS}

All ${ }^{1} \mathrm{H}$-Nuclear Magnetic Resonance (NMR) diffusion experiments were run on a $500 \mathrm{MHz}$ Bruker Avance NEO II spectrometer with a Bruker DIFF BBI probe head at $298 \mathrm{~K}$ (Bruker BioSpin, Rheinstetten, Germany). The free induction decays resulting from the addition of a set of 64 scans $\left(90^{\circ}\right.$ pulse; P1 $=9.57 \mu \mathrm{s}$ ) were Fourier transformed and analysed.

A solution of $20 \%$ Triton $\mathrm{X}-100$ in $\mathrm{D}_{2} \mathrm{O}$ was diluted $1: 1$ with pure $\mathrm{D}_{2} \mathrm{O}$ or a suspension of microcapsules (5 vol\%) in $\mathrm{D}_{2} \mathrm{O}$, respectively, and incubated for five hours at $37{ }^{\circ} \mathrm{C}$. Both samples were centrifuged shortly to remove microcapsules and equal volumes of supernatant were taken for quantitative NMR measurement (qNMR). 7.5 $\mu \mathrm{L}$ of DMSO were added to both samples as internal standard. 


\section{Results and Discussion}
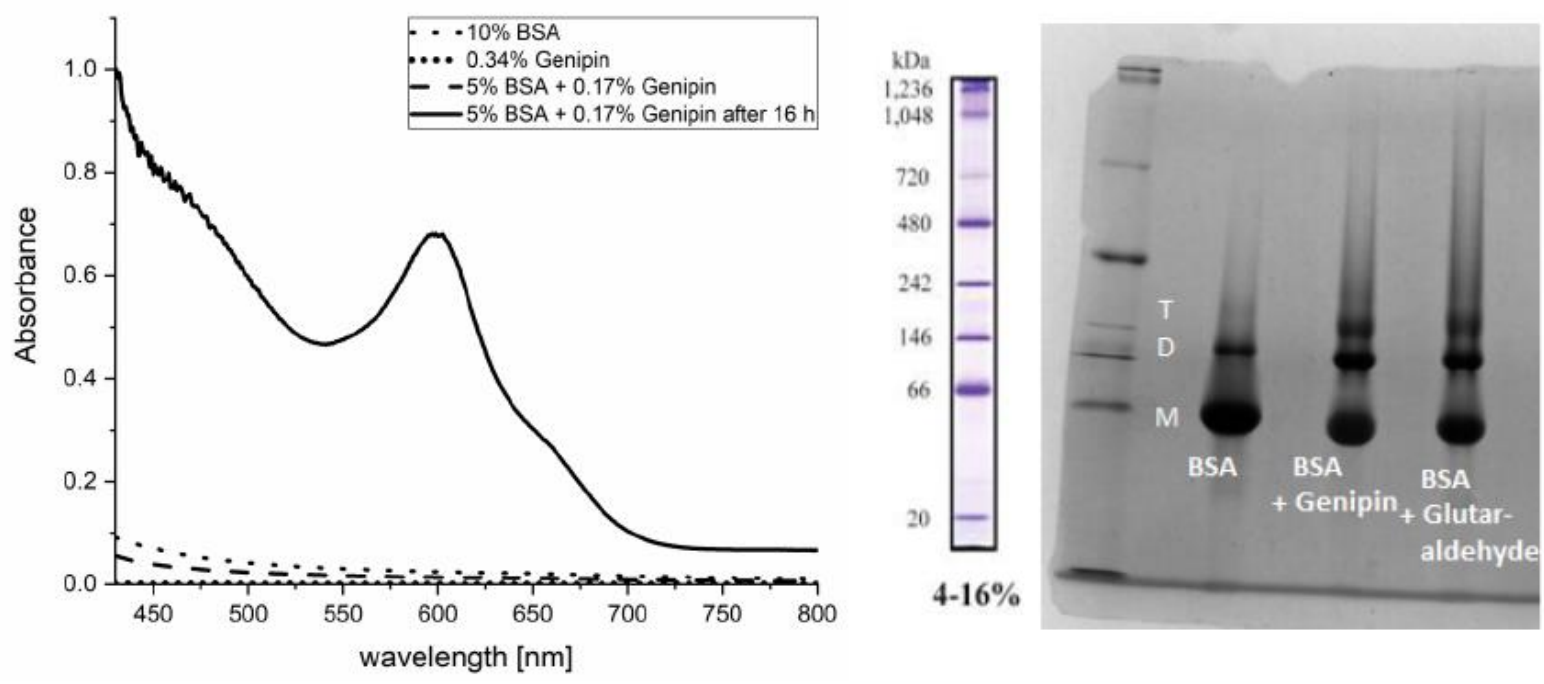

Figure 3. Verification of cross-linking of BSA by genipin. Photometrical spectra of solutions BSA and/or genipin; standardized to a maximum absorbance of 1 (left) and native PAGE of pure BSA, genipin cross-linked BSA and BSA linked by glutaraldehyde as reference (right). M represents monomer BSA, while D represents dimer and T trimer BSA.

Genipin-induced polymerisation of BSA was observable by the change of colour of a shaken solution containing genipin and BSA. The solution of 5\% BSA and 0.17\% genipin equals a molar ratio of 1:10. At the beginning the solution presented a pale-yellow colour attributable to BSA. After 16 hours of shaking at room temperature the colour had turned into a dark green, the combination of residue BSA monomer and the blue colour of oligomerised BSA described in literature (Touyama et al. 1994, Butler et al. 2003, Somers et al. 2008, Yoo et al. 2011). The change in colour was traceable by the appearance of a new signal in the spectrum of the BSA-genipin solution at $599 \mathrm{~nm}$ after the applied reaction period, as seen in Figure 3. The pure solution of BSA showed its highest absorbance in the area of blue and ultraviolet light, while the solution of pure genipin displayed hardly any absorbance in the spectrum of visible light. After merging equal volumes of the two solutions, the resulting spectrum presented the absorbance of a diluted solution of BSA. Cross-linking of BSA by genipin was additionally proven by comparing native PAGE traces of pure BSA and genipin-treated BSA to BSA cross-linked by glutaraldehyde, which is widely known to cross-link proteins (Xiong et al. 2012, Shahgholian et al. 2017). Cross-linking by genipin monitored by native PAGE resulted in a trace virtually identical to that of linking by glutaraldehyde (s. Figure 3 ).

The formation of $\mathrm{Hb}$-microcapsules was started by co-precipitation of $\mathrm{MnCO}_{3}$ together with $\mathrm{Hb}$, induced by mixing equal volumes of solutions containing either $\mathrm{Hb}$ and $\mathrm{MnCl}_{2}$ or $\mathrm{Hb}$ and $\mathrm{Na}_{2} \mathrm{CO}_{3}$, thus forming $\mathrm{MnCO}_{3}$ exceeding its solubility product with a total solubility of $0.065 \mathrm{~g} \cdot \mathrm{L}^{-1}$ (GHS Material Safety Data Sheet for MnCl2 tetrahydrate n.d., GHS Material Safety Data Sheet for MnCO3 n.d., Johnson 1982, Joint Research Centre (European Commission) 2000). Hardly soluble $\mathrm{MnCO}_{3}$ particles rapidly formed around $\mathrm{Hb}$ lead to entrapment of $\mathrm{Hb}$ within these precipitating particles. The subsequent addition of BSA then created a shell around $\mathrm{MnCO}_{3}$ particles by adsorbing onto the surface of the 
particles which was stabilised by a subsequent cross-linking of BSA molecules with either BNBA and DMT-MM or genipin. Cross-linking by BNBA and DMT-MM served in this manuscript as the reference procedure since its whole procedure as its mechanism has formerly been described by LI et al. (Li et al. 2017). The $\mathrm{MnCO}_{3}$ core of the particles was dissolved by complexation of manganese(II) by EDTA resulting in $\mathrm{Hb}$ being surrounded by a shell of cross-linked BSA proteins. In order to dissolve $\mathrm{MnCO}_{3}$, the equilibrium between $\mathrm{Mn}^{2+}$ in solution and $\mathrm{Mn}^{2+}$ bound in solid $\mathrm{MnCO}_{3}$ was used for the synthesis procedure of the particles. The complexation of dissolved $\mathrm{Mn}^{2+}$ by EDTA must disturb this equilibrium. As a consequence of this disturbance, additional soluble $\mathrm{Mn}^{2+}$ is donated from solid $\mathrm{MnCO}_{3}$ in order to reestablish the equilibrium. Since EDTA is present in excess amounts, all soluble $\mathrm{Mn}^{2+}$ should be trapped thereby dissolving all solid $\mathrm{MnCO}_{3}$.

The determination of $\mathrm{Hb}$ concentrations in the stock solution, the first supernatant and the supernatants after each washing step showed that there was hardly any $\mathrm{Hb}$ traceable in the supernatants after each washing step. This result implied that $\mathrm{Hb}$ is tightly enclosed by $\mathrm{MnCO}_{3}$ and that possible pores inside of $\mathrm{MnCO}_{3}$ particles must be chiefly smaller than the diameter of $\mathrm{Hb}$ proteins. The resulting encapsulation efficiency of $\mathrm{Hb}$ inside $\mathrm{MnCO}_{3}$ particles varied from $39-82 \%$ depending on the amount of $\mathrm{Hb}$ initially added to the $\mathrm{Na}_{2} \mathrm{CO}_{3}$ and $\mathrm{MnCl}_{2}$ solutions. The size of the resulting particles did not differ in dependence on the amount of cross-linking reagent added before dissolution of the $\mathrm{MnCO}_{3}$ core. For genipin as cross-linking reagent concentrations of 1, 2, 3 and $4 \mathrm{mM}$ were chosen, all leading to capsules measuring $3-4 \mu \mathrm{m}$ in diameter as measured by DLS (s. Table 1).

Table 1. Particle sizes of HbOCs cross-linked by varying amounts of genipin as measured by DLS. Particle sizes are given as mean value and first (q25) and third (q75) quartile ( $\mathrm{n}=3$ each).

\begin{tabular}{r|l}
$c$ (Genipin) & Particle size given in mean (q25; q75) \\
\hline $1 \mathrm{mM}$ & $3600 \mathrm{~nm}(3370 \mathrm{~nm} ; 3840 \mathrm{~nm})$ \\
$2 \mathrm{mM}$ & $3550 \mathrm{~nm}(3320 \mathrm{~nm} ; 3770 \mathrm{~nm})$ \\
$3 \mathrm{mM}$ & $3490 \mathrm{~nm}(3270 \mathrm{~nm} ; 3700 \mathrm{~nm})$ \\
$4 \mathrm{mM}$ & $3100 \mathrm{~nm}(2804 \mathrm{~nm} ; 3240 \mathrm{~nm})$
\end{tabular}

Cross-linking by BNBA and DMT-MM in DMSO also resulted in particles measuring approximately $3 \mu \mathrm{m}$ in diameter assuming spherical shape of the microcapsules ( $\mathrm{Li}$ et al. 2017), as seen in Figure 4. SEM images of BNBA-DMT-MM and genipin cross-linked particles were taken to depict the structure of the microparticles. Size measurement evaluated by SEM imaging yielded in particles that were seemingly one fourth to one seventh in size compared to measurements performed by DLS. Compared to a normal human RBC whose average size is about $8 \mu \mathrm{m}$ in diameter and $2 \mu \mathrm{m}$ in thickness, the prepared microcapsules have a volume of about $0.000113 \mathrm{fL}$, as measured by SEM, and RBCs are therefore approximately 800,000 times bigger with an average MCV of $94 \mathrm{fL}$ (Diez-Silva et al. 2010). This small size hints at possible suitability for venoclysis. 
bioRxiv preprint doi: https://doi.org/10.1101/818278; this version posted December 27, 2019. The copyright holder for this preprint (which was not certified by peer review) is the author/funder, who has granted bioRxiv a license to display the preprint in perpetuity. It is made available under aCC-BY-NC-ND 4.0 International license.

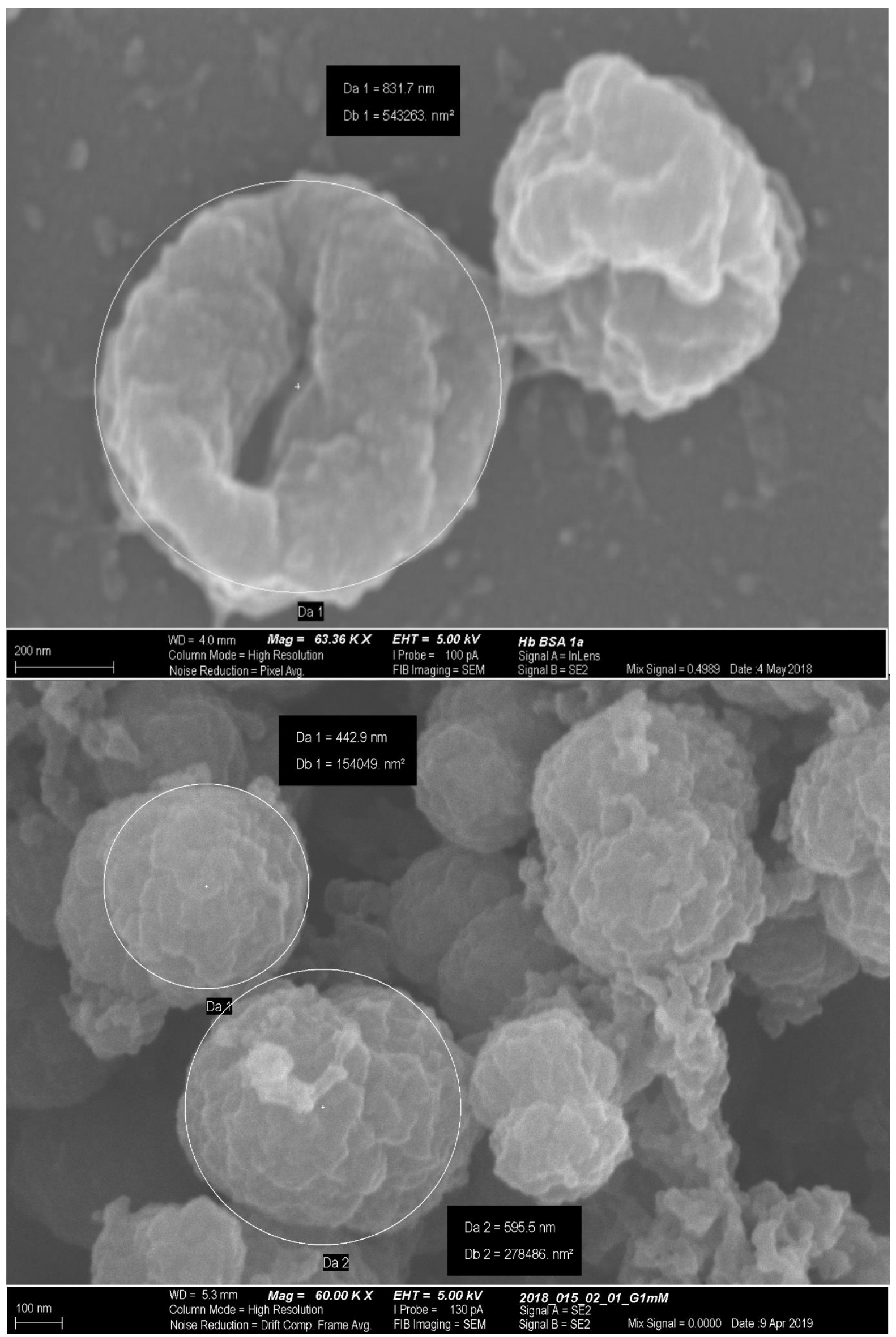

Figure 4. SEM images of HbOCs cross-linked by BNBA and DMT MM (top) and genipin (bottom). Disparity between DLS and SEM size measurements are due to aggregation of capsules at rest. 
Oxygen binding capacity was measured by application of SDT as both reducing agent for methaemoglobin and de-oxygenation agent. The percentage of oxygenation was calculated from the total amount of $\mathrm{Hb}$ applied to the measuring chamber and the decrease in oxygen concentration. Our findings depict that both free $\mathrm{Hb}$ and encapsulated $\mathrm{Hb}$ were finally oxygenated up to $96 \%$. (s. Figure 5).

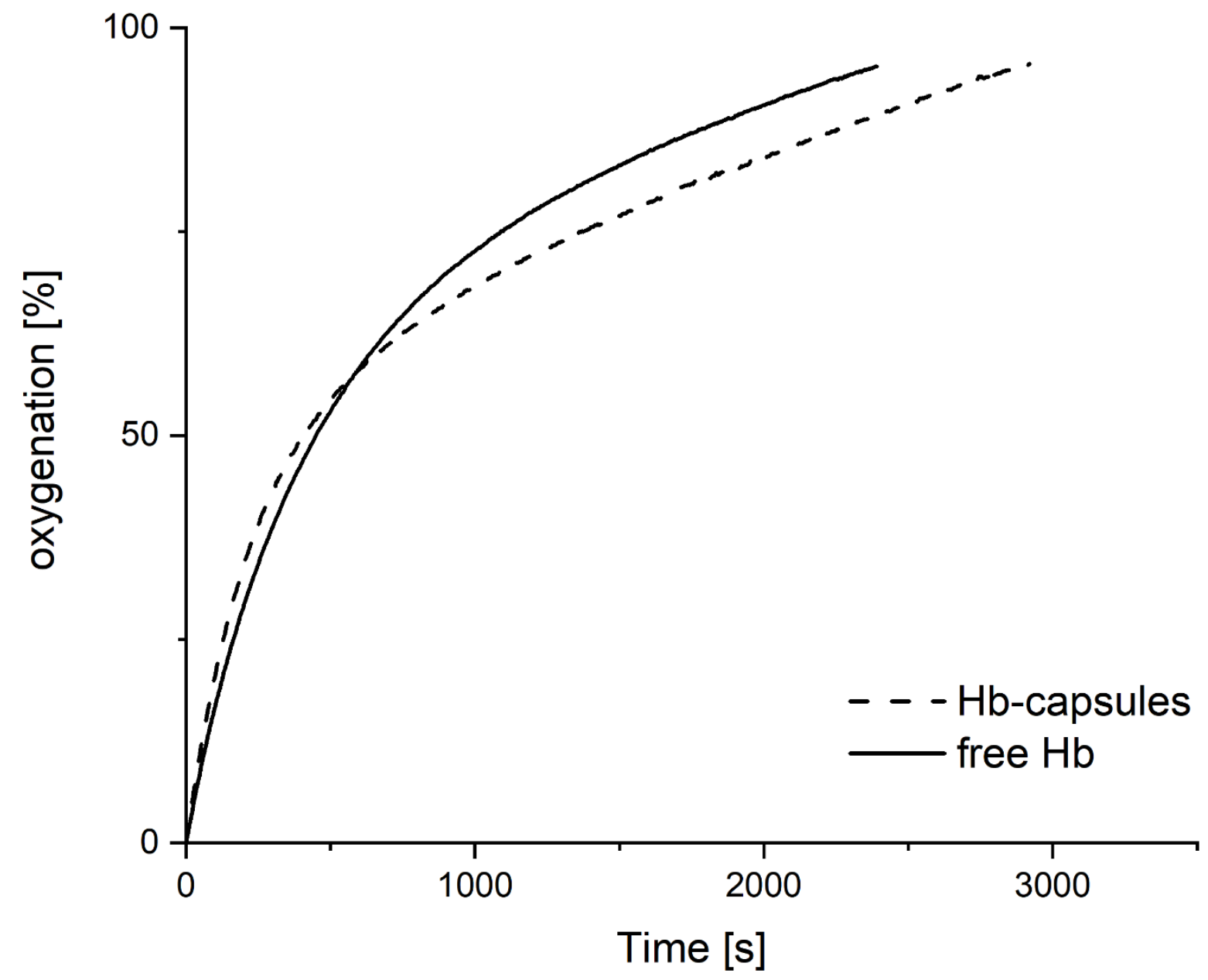

Figure 5. Determination of the oxygen binding capacity of HbOCs compared to the oxygen binding capacity of free $\mathrm{Hb}$. By addition of SDT to HbOCs and $\mathrm{Hb}$ both were deoxygenated and reduced into the active ferrous forms before being injected into the chambers of the respirometer. For reasons of clarity and comprehensibility only one graph is shown exemplary.

In order to provide the purity of the samples, they were checked for possible noxious impurities resulting from the fabrication process. It was checked for residue $\mathrm{Mn}(\mathrm{II})$ and free $\mathrm{Hb}$. First, the samples were washed three times with $30 \mathrm{~mL}$ Millipore water each. Then $\mathrm{Na}_{2} \mathrm{CO}_{3}$ was added to precipitate possible residue $\mathrm{Mn}(\mathrm{II})$. The supernatants were again checked for $\mathrm{Hb}$ by the SDS-Hb-method as described. Any tests failed in either finding Mn(II) or free $\mathrm{Hb}$.

Measurements of LDH-activity before lysis showed slightly increased LDH-activities in supernatants taken from cells previously treated with $\mathrm{HbOCs}$, where cells treated with $5 \mathrm{vol} \%$ of $\mathrm{HbOCs}$ released significantly $(\mathrm{p}=0.014)$ less $\mathrm{LDH}$ than cells treated with $2.5 \mathrm{vol} \%$, yet all $\mathrm{LDH}$-activities were determined to be less than $15 \mathrm{U} / \mathrm{L}$. However, after total lysis induced by Triton X-100, cells treated with 5 vol\% of HbOCs displayed significantly $\left(\mathrm{p}=4.2 \cdot 10^{-8}\right)$ lower LDH-activities than any other group of 
cells tested (s. Figure 6). This was not the case when cells were incubated with an equal amount of free $\mathrm{Hb}$ (data not shown). Free $\mathrm{Hb}$ concentration was calculated as about $4.4 \cdot 10^{11}$ capsules per microliter (5 vol\% HbOCs) based on SEM measurements (s. Figure 4). Comparison of relative cell damage revealed no damage of more than $5.2 \%$ in any treatment group (s. Figure 6), although treatment with $5 \mathrm{vol} \%$ HbOCs seems to have a minor but significant $(\mathrm{p}=0.03)$ impact on relative cell damage. There is no evidence of any impact of the incubation duration on absolute cell damage. Remarkably, there is lower relative cell damage after three hours of incubation, although that group of cells already displayed lower total LDH-release. Nonetheless, this difference is still statistically insignificant. Compared to the 'blank' group, p is 0.26 for g-BSA, 0.60 for 2.5 vol $\%$ and 0.72 for 5 vol $\%$. When g-BSA is used as reference p-values drop to 0.17 for 2.5 vol\% and 0.03 for 5 vol\%.
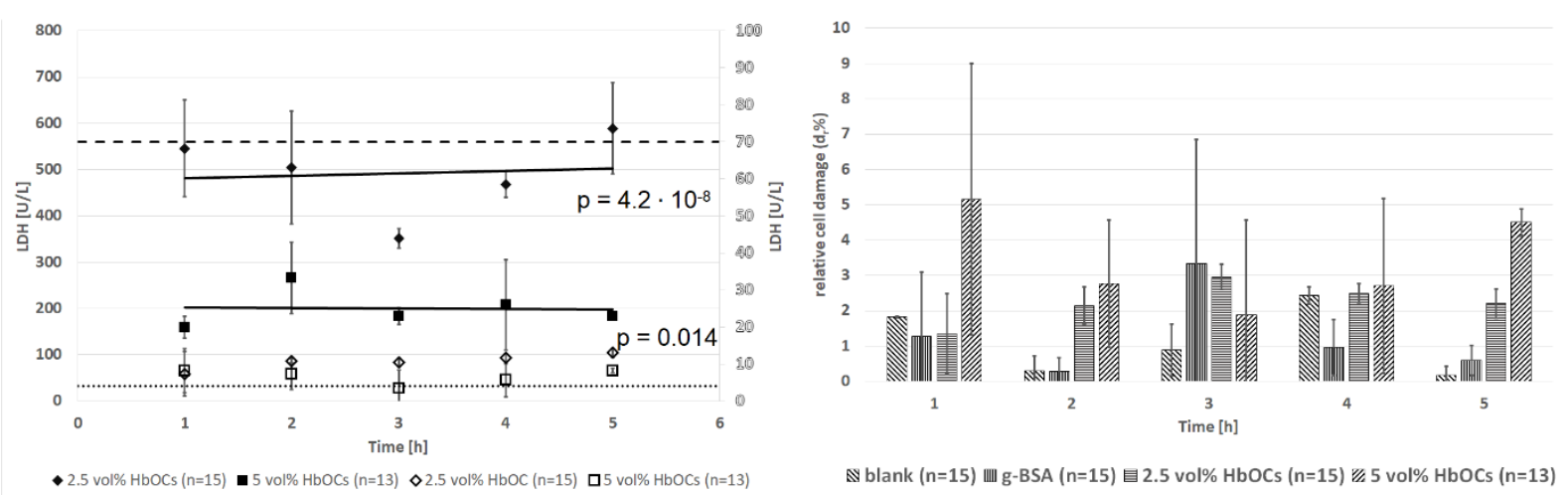

Figure 6. LDH-activities as a general marker of cell damage after treatment with BSA or HbOCs in different concentrations. A solution of $4.5 \mathrm{~g} / \mathrm{L}$ glucose in Ringer's solution served as blank. Either $3 \mathrm{mg} / \mathrm{mL}$ BSA (g-BSA) or a suspension of 2.5 vol\% or 5 vol\% HbOCs was added. Before (empty symbols; right y-axis) and after total lysis of cells (filled symbols; left y-axis) induced by addition of $200 \mu \mathrm{L} \mathrm{25 \%}$ Triton X-100 as detergent. The dotted line represents the average LDH-activity of the untreated control cells (blank) before lysis. The dashed line represents the average LDH-activity of the untreated control cells (blank) after lysis (LDHmax). The relative damage has been calculated as described in methods. T-tests were performed between groups treated with $2.5 \mathrm{vol} \%$ and $5 \mathrm{vol} \% \mathrm{HbOCs}$. Data is shown +- 1 standard deviation ( 5 vol\% HbOCs $n=13$; all other $n=15)$.

In order to investigate any interference of microcapsules with the LDH assay, standard testing solutions (DiaSys Diagnostic Systems GmbH, Holzheim, Germany) containing commonly tested parameters for clinical purposes with known and well defined activities or concentrations, respectively, were incubated $1: 1$ and $1: 9$ for $1 \mathrm{~h}$ at $37{ }^{\circ} \mathrm{C}$ with microcapsules suspension ( 5 vol\%) or Ringer's solution, respectively. ( $\mathrm{n}=3$ each; s. Table 2 and Table 3). There were no significant differences in any parameters whether microcapsules had been added or not ( $p>0.1$ in any group, s. Table 2 and Table 3$)$. 
Table 2. Testing on interaction between clinical standard parameters and prepared HbOCs. Ratio between standard testing serum and microcapsules suspension or Ringer's solution, respectively, 1:1. All samples were incubated for $1 \mathrm{~h}$ at $37^{\circ} \mathrm{C}(\mathrm{n}=3)$.

Diluted (1:1) with

\begin{tabular}{l|rr|rr|c}
\hline \multirow{2}{*}{ Parameter } & \multicolumn{2}{|c|}{ Ringer's solution [U/L] } & \multicolumn{2}{c|}{ HbOCs [U/L] } & $\mathrm{n}=3$ \\
\cline { 2 - 5 } & Mean value & \multicolumn{2}{c|}{$\begin{array}{c}\text { Standard } \\
\text { deviation }\end{array}$} & Mean value & \multicolumn{2}{c}{$\begin{array}{l}\text { Standard } \\
\text { deviation }\end{array}$} & $\mathrm{p}$ \\
AST & 108.7 & 2.0 & 110.9 & 1.4 & 0.27 \\
CK & 132.5 & 2.8 & 135.5 & 2.0 & 0.29 \\
Crea & 210.8 & 3.7 & 216.1 & 1.7 & 0.17 \\
LDH & 3.64 & 0.11 & 3.68 & 0.09 & 0.71 \\
Urea & 222.1 & 4.9 & 219.7 & 7.4 & 0.72 \\
& 120.4 & 1.6 & 123.1 & 1.0 & 0.12
\end{tabular}

Table 3. Testing on interaction between clinical standard parameters and prepared HbOCs. Ratio between standard testing serum and microcapsules suspension or Ringer's solution, respectively 1:9. All samples were incubated for $1 \mathrm{~h}$ at $37^{\circ} \mathrm{C}(\mathrm{n}=3)$.

Diluted (1:9) with

\begin{tabular}{l|rr|rr|c}
\hline & \multicolumn{2}{|c|}{ Ringer's solution [U/L] } & \multicolumn{2}{|c|}{ HbOCs [U/L] } & $\mathrm{n}=3$ \\
Parameter & Mean value & \multicolumn{2}{c|}{$\begin{array}{l}\text { Standard } \\
\text { deviation }\end{array}$} & Mean value & \multicolumn{2}{c}{$\begin{array}{l}\text { Standard } \\
\text { deviation }\end{array}$} & $\mathrm{p}$ \\
ALT & 22.5 & 0.4 & 22.2 & 0.6 & 0.58 \\
$A S T$ & 26.8 & 1.3 & 27.3 & 0.4 & 0.62 \\
CK & 43.0 & 2.1 & 42.6 & 0.3 & 0.80 \\
Crea & 0.53 & 0.06 & 0.54 & 0.00 & 0.83 \\
LDH & 53.7 & 4.1 & 48.1 & 0.0 & 0.19 \\
Urea & 23.8 & 1.4 & 24.5 & 0.7 & 0.58
\end{tabular}

To investigate the difference of LDH release after incubation with 2.5 and 5 vol\% of HbOCs, qNMR was performed for ruling out binding of Triton X-100 by HbOCs (s. Figure 7). Addition of $7.5 \mu \mathrm{L}$ DMSO to $1 \mathrm{~mL}$ of $10 \%$ Triton X-100 in D2O results in $100 \mathrm{mM}$ DMSO and $161 \mathrm{mM}$ Triton X-100. After incubation of Triton X-100 solution with $\mathrm{HbOCs}$ at $37{ }^{\circ} \mathrm{C}$ no decrease in Triton X-100 concentration was determined. The resulting ratio between Triton X-100 and DMSO was determined to be 1.61 irrespectively of pre-incubation of Triton X-100 with capsules. These data clearly show, that microcapsules did not bind Triton X-100. Therefore, in the LDH assay (s. Figure 5), all cells were lysed with the same concentration of Triton X-100, irrespectively of the presence of no, 2.5 or 5 vol\% of HbOCs. In conclusion, qNMR measurements of Triton X-100 did not further elucidate the difference in LDH release after treatment with different amounts of HbOCs, thus at the moment there is no valid explanation for this limitation of LDH-release, that is already observed within the first hour. Evaluation of interference of HbOCs and their delivered oxygen with (intra-)cellular signalling pathways could be 
the next step in understanding the limitation in total LDH-activities after treatment with higher doses of HbOCs.
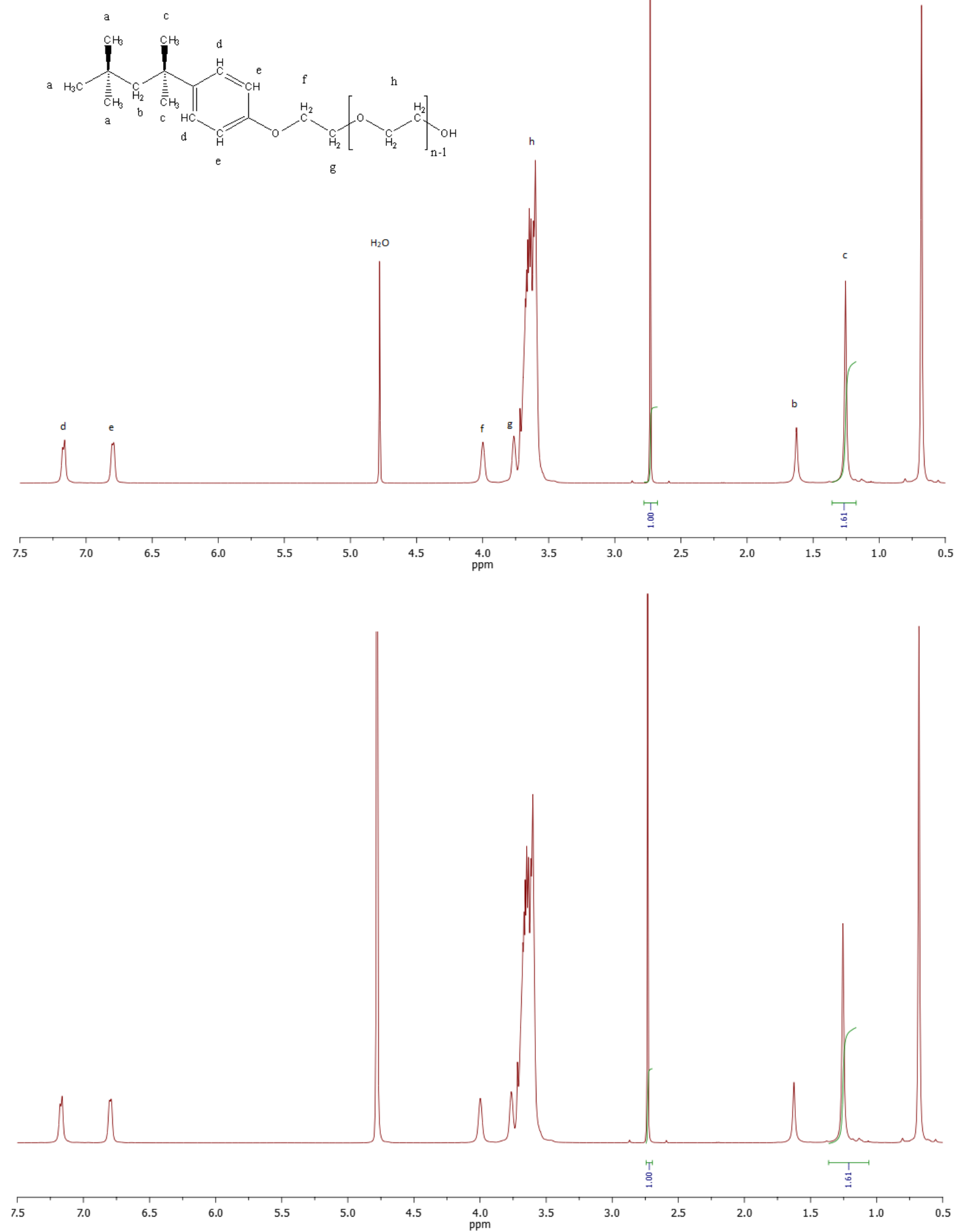

Figure 7. qNMR of $10 \%$ Triton X-100 with DMSO as internal standard. Without incubation (top) and after incubation over night with $5 \mathrm{vol} \% \mathrm{HbOCs}$ (bottom). ${ }^{1} \mathrm{H}-\mathrm{NMR}\left(500 \mathrm{MHz}, \mathrm{D}_{2} \mathrm{O}\right) \delta 7.17$ (d, J = 7.2 $\mathrm{Hz}, 2 \mathrm{H}), 6.80(\mathrm{~d}, \mathrm{~J}=6.0 \mathrm{~Hz}, 2 \mathrm{H}), 4.00(\mathrm{~s}, 2 \mathrm{H}), 3.76(\mathrm{~s}, 2 \mathrm{H}), 3.73-3.43(\mathrm{~m}, 36 \mathrm{H}), 1.63(\mathrm{~s}, 2 \mathrm{H}), 1.26(\mathrm{~s}$, $6 \mathrm{H}), 0.68(\mathrm{~s}, 9 \mathrm{H})$. 
Since BSA contains the basic amino acid lysin 59 times, it offers up to 60 amino-groups for cross-linking (Hirayama et al. 1990). Two amino groups are cross-linked by one molecule of genipin or other cross-linking agents, so that the maximum ratio of BSA:genipin equals 1:30. Using $1 \mathrm{mM}$ genipin as described, equals a ratio of approximately 1:27 which is close to maximum cross-linkage. This results in an undesired linkage of two or more individual capsules.

In order to supress the artificial linkage of individual capsules, the applied amount of genipin was optimised. Further reduction of the amount of genipin used for cross-linking yielded in capsules with smaller diameters according to evaluation with DLS. A molecular ratio of 1:10 was found to result in two nearly Gaussian distributions with modes of $1230 \mathrm{~nm}$ and $2069 \mathrm{~nm}$. Due to the small difference between the two modes, quartiles of the two distributions are overlapping. For the whole distribution only one percent of capsules is smaller than $690 \mathrm{~nm}$ and only one percent is bigger than $3400 \mathrm{~nm}$. Further reduction of the BSA:genipin ratio down to 1:5 yielded in capsules displaying a similar distribution to those of ratio 1:10 but modes of the resulting fractions were torn apart to $989 \mathrm{~nm}$ and $2627 \mathrm{~nm}$. On the one hand capsules were less cross-linked among each other, on the other hand the number of capsules linked incompletely also increased. Because of these findings, the amount of genipin cannot be further decreased. The optimal encapsulation efficiency was reached at concentrations of $0.1 \mathrm{M} \mathrm{Na}_{2} \mathrm{CO}_{3}$ and $\mathrm{MnCl}_{2}$ as well as $5 \mathrm{mg} \cdot \mathrm{mL}^{-1} \mathrm{Hb}$ and $0.5 \mathrm{mg} \cdot \mathrm{mL}^{-1} \mathrm{BSA}$, yielding in $40-45 \%$ of encapsulated $\mathrm{Hb}$. Further increase in $\mathrm{Hb}$-concentration did not increase the absolute amount of encapsulated $\mathrm{Hb}$. Further decrease in $\mathrm{Hb}$-concentration led to higher encapsulation efficiencies but less encapsulated $\mathrm{Hb}$ in total.

Zeta-potential calculated for capsules prepared by the partly optimised method presented above yielded in $\zeta=-37.49 \pm 1.25 \mathrm{mV}$ given as mean \pm standard deviation $(\mathrm{n}=5)$. For the process of calculation, HbOCs were dissolved in $1 \mathrm{~mL}$ MilliQ water resulting in a concentration of approximately 1.2 vol\% HbOCs. Each sample was calculated three times.

Albumin microcapsules containing haemoglobin prepared by the method presented can undergo oxidation of ferrous haemoglobin to ferric methaemoglobin just as it is naturally occurring in erythrocytes. It was shown that ferric methaemoglobin can be recovered easily by application of excess ascorbic acid or SDT in a non-enzymatic reaction, which is suggesting a long-term functionality of haemoglobin microcapsules prepared by the method presented (s. Figure 8). Due to the permeability of the albumin shell for small molecules, co-encapsulation of ascorbic acid together with haemoglobin is obviously not a mandatory prerequisite. Addition of ascorbic acid to a suspension of microcapsules right before application for venoclysis could present a suitable method to provide blood-levels of ascorbic acid high enough to re-reduce potentially oxidised ferric methaemoglobin. 


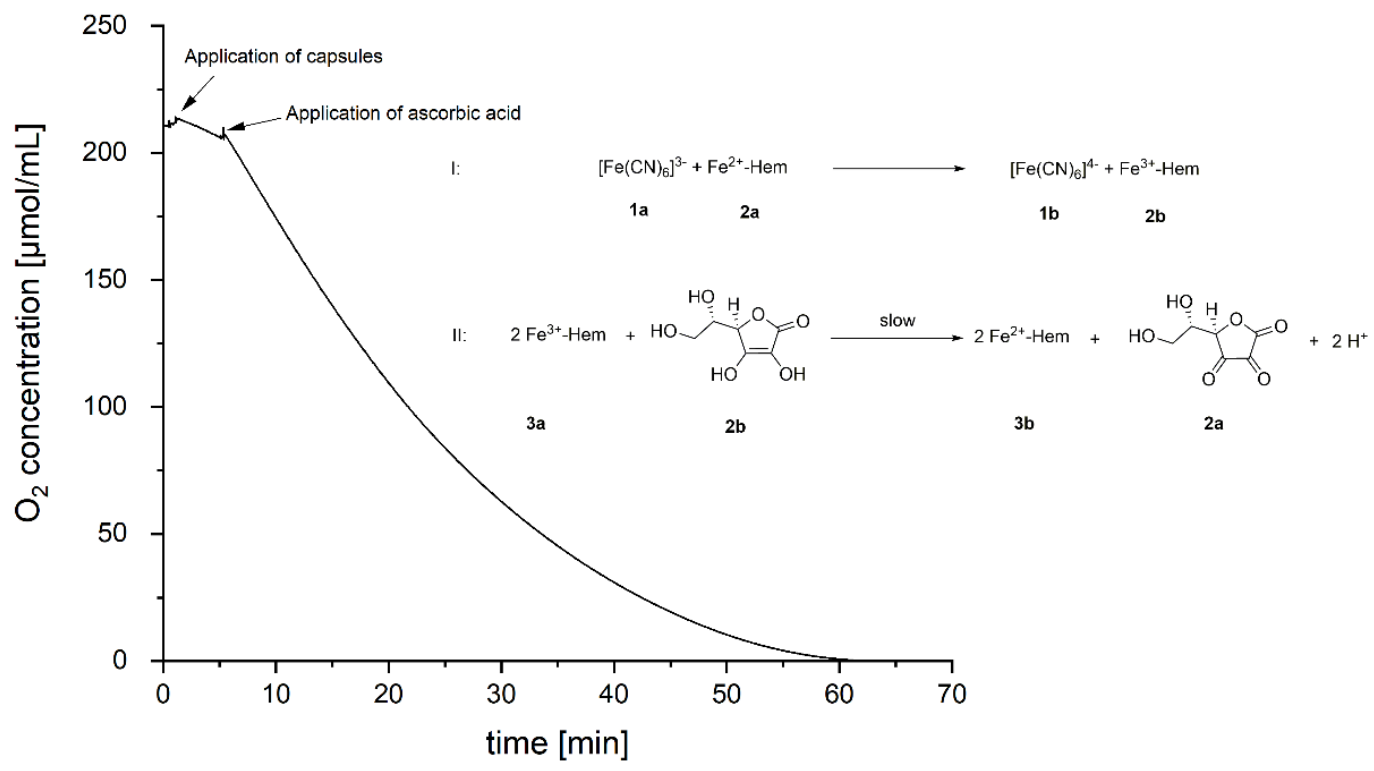

Figure 8. Testing on functionality by respirometry; Observation of change in oxygen concentration after application of HbOCs and ascorbic acid into the respirometer. I: Oxidation of ferrous haemoglobin (2a) by the ferricyanide anion (1a) to form the ferrocyanide ion (1b) and methaemoglobin (2b). II: Reduction of two equivalents of methaemoglobin iron (2b) by one molecule of ascorbic acid (3a) to form ferrous haemoglobin (2a) and dehydroascorbic acid (3b). For reasons of clarity and comprehensibility only one graph is shown exemplary.

\section{Conclusion}

The preparation of $\mathrm{Hb}$-microcapsules by the method presented leads to a promising type of artificial blood substitute. In vitro experiments showed a good biocompatibility of the applied microcapsules because any damage parameters remained to be almost silent. Nevertheless, the procedure is currently further optimised in order to receive particles with a somewhat smaller diameter. Therefore, interindividual cross-linking among capsules as well as aggregation of solitary capsules into larger clusters must be prevented for future use.

In any case, we demonstrated here for the first time, that the preparation of genipin-linked albumin microcapsules as potential artificial oxygen carriers is possible in absence of harmful cross-linking agents like glutaraldehyde.

\section{Acknowledgements}

The authors thankfully express their gratitude to Mrs. Sylvia Voortmann of the Electron Microscopy Unit of the Imaging Center Essen (IMCES) for performance of SEM imaging, Mrs. Susanne Eitner from the Institute of Physiological Chemistry, University of Duisburg-Essen, University Hospital Essen (Essen) for performing Native PAGE and cell culture, Mrs. Birgit Podleska from the Institute of Physiological Chemistry, University of Duisburg-Essen, University Hospital Essen (Essen) for culturing cells and Mrs. Eva Hillen from the Institute of Physiological Chemistry, University of Duisburg-Essen, University Hospital Essen (Essen) for measurement of LDH-activity. 


\section{Disclosure of Interests}

The authors report no conflict of interests.

\section{References}

Bauer, J., Zähres, M., Zellermann, A., Kirsch, M., Petrat, F., de Groot, H., and Mayer, C., 2010. Perfluorocarbon-filled poly(lactide-co-gylcolide) nano- and microcapsules as artificial oxygen carriers for blood substitutes: a physico-chemical assessment. Journal of Microencapsulation, 27 (2), 122-132.

Butler, M.F., Ng, Y., and Pudney, P.D.A., 2003. Mechanism and kinetics of crosslinking reaction between biopolymers containing primary amine groups and genipin. Journal of Polymer Science, Part A: Polymer Chemistry, (December 2003), 3941-3953.

Bychkova, A. V., Rosenfeld, M.A., Leonova, V.B., Sorokina, O.N., Lomakin, S.M., and Kovarski, A.L., 2013. Free-radical cross-linking of serum albumin molecules on the surface of magnetite nanoparticles in aqueous dispersion. Colloid Journal, 75 (1), 7-13.

Chang, T.M.S., 2006. Blood substitutes based on nanobiotechnology. Trends in Biotechnology, 24 (8), $372-377$.

Chen, J.-Y., Scerbo, M., and Kramer, G., 2009. A review of blood substitutes: examining the history, clinical trial results, and ethics of hemoglobin-based oxygen carriers. Clinics, 64 (8), 803-13.

Choi, J.H., Chen, K.H., and Strano, M.S., 2006. Aptamer-capped nanocrystal quantum dots: A new method for label-free protein detection. Journal of the American Chemical Society, 128 (49), 15584-15585.

Chung, K.-W., Basavaraju, S. V, Mu, Y., van Santen, K.L., Haass, K.A., Henry, R., Berger, J., and Kuehnert, M.J., 2016. Declining blood collection and utilization in the United States. Transfusion, $56(9), 2184-92$.

Diez-Silva, M., Dao, M., Han, J., Lim, C.-T., and Suresh, S., 2010. Shape and Biomechanical Characteristics of Human Red Blood Cells in Health and Disease. MRS Bulletin, 35 (05), 382-388.

Djerassi, C., Gray, J.D., and Kincl, F.A., 1960. Naturally Occurring Oxygen Heterocyclics. IX. Isolation and Characterization of Genipin. Journal of Organic Chemistry, 25 (12), 2174-2177.

Drabkin, D. and Austin, J.H., 1932. Spectrophotometry of Hemoglobin. The Journal of Biological Chemistry, 98 (14), 719-733.

Ellingson, K.D., Sapiano, M.R.P., Haass, K.A., Savinkina, A.A., Baker, M.L., Chung, K.-W., Henry, R.A., Berger, J.J., Kuehnert, M.J., and Basavaraju, S. V, 2017. Continued decline in blood collection and transfusion in the United States-2015. Transfusion, 57 Suppl 2 (Suppl 2), 15881598.

Ferenz, K.B. and Steinbicker, A.U., 2019. Artificial oxygen carriers- past, present and the future-a review of the most innovative and clinically relevant concepts. The Journal of pharmacology and 
experimental therapeutics, jpet.118.254664.

Ferenz, K.B., Waack, I.N., Mayer, C., de Groot, H., and Kirsch, M., 2013. Long-circulating poly(ethylene glycol)-coated poly(lactid-co-glycolid) microcapsules as potential carriers for intravenously administered drugs. Journal of Microencapsulation, 30 (7), 632-642.

García-Roa, M., Del Carmen Vicente-Ayuso, M., Bobes, A.M., Pedraza, A.C., González-Fernández, A., Martín, M.P., Sáez, I., Seghatchian, J., and Gutiérrez, L., 2017. Red blood cell storage time and transfusion: current practice, concerns and future perspectives. Blood transfusion $=$ Trasfusione del sangue, 15 (3), 222-231.

GHS Material Safety Data Sheet for MnCl2 tetrahydrate, n.d.

GHS Material Safety Data Sheet for MnCO3, n.d.

Henseler, O., 2019. Report on notifications pursuant to Section 21 TFG (German Transfusion Act) for 2012 to 2017 [online]. Available from: https://www.pei.de/EN/information/bloodsupply/reports/report-blood-supply-2012-2016-21tfg-content.html?nn=3251266 [Accessed 21 Feb 2019].

Hirayama, K., Akashi, S., Furuya, M., and Fukuhara, K., 1990. Rapid confirmation and revision of the primary structure of bovine serum albumin by ESIMS and frit-FAB LC/MS. Biochemical and Biophysical Research Communications, 173 (2), 639-646.

Instructions for use (respons 920) [online], 2019. Available from: https://www.diasysdeutschland.de/produkte/systemkits/kits-fuer-responsr/product-details/95-ldh-fsifcc/product.show [Accessed 22 Oct 2019].

Johnson, K.S., 1982. Solubility of rhodochrosite (MnCO3) in water and seawater. Geochimica et Cosmochimica Acta, 46 (10), 1805-1809.

Joint Research Centre (European Commission), 2000. IUCLID CD-ROM, Year 2000 edition. Ispra, Italy: Joint Research Centre (European Commission).

Kalyan Chakravarthy, V., Naveen Chandra, D., Santhoshi Prasanna, B., Jaya Mastan Rao, T., and Ranga Rao, D., 2012. Haemoglobin estimation by non-cyanide methods. Journal of Clinical and Diagnostic Research, 6 (6), 955-958.

van Kampen, E. and Zijlstra, W.G., 1961. Standardization of hemoglobinometry. II. The hemiglobincyanide method. Clinica chimica acta; international journal of clinical chemistry, 6 , $538-44$.

Karsan, A., Maclaren, I., Conn, D., and Wadsworth, L., 1993. An Evaluation of Hemoglobin Determination Using Sodium Lauryl Sulfate. American Journal of Clinical Pathology, 100 (2), $123-126$.

Lambert, J.H., 1760. Photometria, sive de mensura et gradibus luminis, colorum et umbrae. Augsburg: Sumptibus Vidae Eberhardi Klett.

Li, H., Xiong, Y., Zhang, Y., Tong, W., Georgieva, R., Bäumler, H., and Gao, C., 2017. PhotoDecomposable Sub-Micrometer Albumin Particles Cross-Linked by ortho -Nitrobenzyl 
Derivatives. Macromolecular Chemistry and Physics, 1700413.

Ling, N.R., 1961. The Attachment of Proteins to Aldehyde-Tanned Cells. British Journal of Haematology, 7 (3), 299-302.

Lomonosova, E.E., Kirsch, M., and de Groot, H., 1998. Calcium vs. iron-mediated processes in hydrogen peroxide toxicity to 1929 cells: effects of glucose. Free Radical Biology and Medicine, 25 (4-5), 493-503.

Mamedova, N.N., Kotov, N.A., Rogach, A.L., and Studer, J., 2002. Albumin-CdTe Nanoparticle Bioconjugates: Preparation, Structure, and Interunit Energy Transfer with Antenna Effect. Nano Letters, 1 (6), 281-286.

Müller, M.M., Geisen, C., Zacharowski, K., Tonn, T., and Seifried, E., 2015. Transfusion of Packed Red Cells. Deutsches Aerzteblatt Online.

Njoku, M., St Peter, D., and Mackenzie, C.F., 2015. Haemoglobin-based oxygen carriers: indications and future applications. British journal of hospital medicine (London, England : 2005), 76 (2), 78 83.

Oshiro, I., Takenaka, T., and Maeda, J., 1982. New method for hemoglobin determination by using sodium lauryl sulfate (SLS). Clinical biochemistry, 15 (2), 83-8.

Remy, K.E. and Spinella, P.C., 2016. Red blood cell storage age - what we know from clinical trials. Expert Review of Hematology, 9 (11), 1011-1013.

Riedel, S., Hinz, A., and Schwarz, R., 2000. Einstellung zur Blutspende in Deutschland - Ergebnisse einer repräsentativen Untersuchung. Transfusion Medicine and Hemotherapy, 27 (4), 196-199.

Ruchalla, E., 2013. Verhalten von Blutspendern - Warum hören Blutspender auf, Blut zu spenden? Transfusionsmedizin - Immunhämatologie, Hämotherapie, Immungenetik, Zelltherapie, 03 (01), $7-8$.

Sakai, H., Ng, K., Li, B., and Sugimura, N., 2013. Swine hemoglobin as a potential source of artificial oxygen carriers, hemoglobin-vesicles. Artificial cells, nanomedicine, and biotechnology, 41 (1), $37-41$.

Shahgholian, N., Rajabzadeh, G., and Malaekeh-Nikouei, B., 2017. Preparation and evaluation of BSAbased hydrosol nanoparticles cross-linked with genipin for oral administration of poorly watersoluble curcumin. International Journal of Biological Macromolecules, 104 (Pt A), 788-798.

Sharma, S., Sharma, P., and Tyler, L.N., 2011. Transfusion of blood and blood products: indications and complications. American family physician, 83 (6), 719-24.

Somers, P., De Somer, F., Cornelissen, M., Bouchez, S., Gasthuys, F., Narine, K., Cox, E., and Van Nooten, G., 2008. Genipin blues: an alternative non-toxic crosslinker for heart valves? The Journal of heart valve disease, 17 (6), 682-8.

Stephan, C., Schlawne, C., Grass, S., Waack, I.N., Ferenz, K.B., Bachmann, M., Barnert, S., Schubert, R., Bastmeyer, M., de Groot, H., and Mayer, C., 2014. Artificial oxygen carriers based on perfluorodecalin-filled poly( $n$-butyl-cyanoacrylate) nanocapsules. Journal of 
Microencapsulation, 31 (3), 284-292.

von Storp, B., Engel, A., Boeker, A., Ploeger, M., and Langer, K., 2012. Albumin nanoparticles with predictable size by desolvation procedure. Journal of Microencapsulation, 29 (2), 138-146.

Taguchi, K., Yamasaki, K., Maruyama, T., and Otagiri, M., 2017. Comparison of the Pharmacokinetic Properties of Hemoglobin-Based Oxygen Carriers. Journal of functional biomaterials, 8 (1), 11.

Touyama, R., Inoue, K., Takeda, Y., Yatsuzuka, M., Ikumoto, T., Moritome, N., Shingu, T., Yokoi, T., and Inouye, H., 1994. Studies on the Blue Pigments Produced from Genipin and Methylamine. II. On the Formation Mechanisms of Brownish-Red Intermediates Leading to the Blue Pigment Formation. Chemical \& Pharmaceutical Bulletin, 42 (8), 1571-1578.

Wrobeln, A., Laudien, J., Groß-Heitfeld, C., Linders, J., Mayer, C., Wilde, B., Knoll, T., Naglav, D., Kirsch, M., and Ferenz, K.B., 2017. Albumin-derived perfluorocarbon-based artificial oxygen carriers: A physico-chemical characterization and first in vivo evaluation of biocompatibility. European Journal of Pharmaceutics and Biopharmaceutics, 115, 52-64.

Wrobeln, A., Schlüter, K.D., Linders, J., Zähres, M., Mayer, C., Kirsch, M., and Ferenz, K.B., 2017. Functionality of albumin-derived perfluorocarbon-based artificial oxygen carriers in the Langendorff-heart. Artificial Cells, Nanomedicine, and Biotechnology, 45 (4), 723-730.

Xiong, Y., Liu, Z.Z., Georgieva, R., Smuda, K., Steffen, A., Sendeski, M., Voigt, A., Patzak, A., and Bäumler, H., 2013. Nonvasoconstrictive Hemoglobin Particles as Oxygen Carriers. ACS Nano, 7 (9), 7454-7461.

Xiong, Y., Steffen, A., Andreas, K., Müller, S., Sternberg, N., Georgieva, R., and Bäumler, H., 2012. Hemoglobin-Based Oxygen Carrier Microparticles: Synthesis, Properties, and In Vitro and In Vivo Investigations. Biomacromolecules, 13 (10), 3292-3300.

Yoo, J.S., Kim, Y.J., Kim, S.H., and Choi, S.H., 2011. Study on genipin: A new alternative natural crosslinking agent for fixing heterograft tissue. Korean Journal of Thoracic and Cardiovascular Surgery, 44 (3), 197-207. 